СОКОЛОВ Вадим Вячеславович - кандидат исторических наук, доцент; доцент кафедры политологии и государственной политики Среднерусского института управления - филиала Российской академии народного хозяйства и государственной службы при Президенте РФ (302028, Россия, 2. Opeл, б-р Победы, 5a; politgmu@таil.ru)

\title{
К ВОПРОСУ О КАТЕГОРИИ ЭФФЕКТИВНОСТИ В ДЕЯТЕЛЬНОСТИ ОРГАНОВ ВЛАСТИ И УПРАВЛЕНИЯ В РОССИЙСКОМ И ЗАРУБЕЖНОМ НАУЧНЫХ ДИСКУРСАХ
}

Аннотация. В данной статье рассматриваются категории, характеризующие проблематику эффективности в сфере управления. Автор анализирует такие понятия, как «политическое», "управление», "органы власти», «эффективность» в англосаксонской и отечественной политической науке. Понятие «эффективность» рассматривается и как универсальная управленческая категория, и как единица системы государственного управления. На основе проведенного анализа выявляется причинно-следственная связь между политическими условиями и повышением эффективности деятельности органов власти и управления в РФ.

Ключевые слова: политическое, управление, государственное управление, органы власти, эффективность

$\mathrm{H}$ аправленность, динамика и результативность социально-экономического развития России и ее регионов поставила на повестку дня актуальный вопрос о совершенствовании системы государственного управления на федеральном и региональном уровнях. Фактически речь идет о выявлении условий и факторов, повышающих эффективность или создающих дополнительные проблемы в функционировании государственных институтов. Особый ракурс при рассмотрении данного вопроса - политические условия. И в этой связи важно, во-первых, определить ключевые понятия и категории при решении поставленной автором исследовательской задачи (понятия «политическое», «управление», «органы власти», «эффективность» и др.); во-вторых, выявить причинно-следственную связь между политическими условиями и повышением эффективности деятельности органов власти и управления в РФ.

Еще в 20-30-х гг. XX в. К. Шмитт, вводя в научный оборот понятие «политическое», определил, что эта категория имеет свои собственные критерии, своеобразный эффект которых «проявляется в противоположность различным относительно самостоятельным предметным областям человеческого мышления и действования, особенно в противоположность моральному, эстетическому, экономическому» [Шмитт 2016: 301]. Таким образом, для К. Шмитта понятие политического - это политическое действование. Причем, по мнению автора, в разрезе моральных различений это суть «доброе» и «злое», в эстетическом - «прекрасное» и «безобразное», в экономическом - «полезное» и «вредное» или «рентабельное» и «нерентабельное».

Стоит также отметить, что в традициях англосаксонской политической науки используется несколько понятий политического. С таким подходом согласны и ряд российских политологов (С.В. Патрушев, Л.Е. Филиппова). К примеру, «politics - политика как общественное явление, процесс; policy - политика как содержание, программа, направление (курс) действий; polity - политика как полития, форма, устройство или образ правления» [Конструирование современной... 2018: 11]. 
Таким образом, политические условия применительно к национальным государствам и их территориям (регионам) - это конкретная ситуация и политическое поле, в рамках которых функционируют субъекты политики (акторы). Их действования (по К. Шмитту) и определяют диспозиции и конструкции. При таком подходе функционирование политических акторов может быть (опять же по К. Шмитту) «добрым» и «злым» в рамках моральных различений и «полезным» и «вредным» - в экономическом плане.

Если рассматривать систему государственного управления в постсоветской России как на федеральном, так и на региональном уровнях, то стоит отметить следующее. С одной стороны, и в период 1990-х гг., и в период нулевых ее нельзя считать эффективной с точки зрения результатов социально-экономического развития страны, повлиявших на качество и уровень жизни населения. С другой стороны, ключевым аргументом в пользу предыдущего тезиса стоит считать перманентные реформы данной системы, осуществлявшиеся политическим руководством страны с целью повышения ее позитивной результативности.

Важно привести цифровые показатели того, что представляла и представляет собой эта система. В период позднего СССР и начала рыночных реформ в РФ (1985-1994 гг.) число чиновников как символа бюрократии сначала «упало с 8,7 до 6,8 государственных служащих на 1000 человек. А с 2000 по 2014 год подскочило с 7,9 до 15,4 человека на 1000 жителей»1. Имеет смысл привести и современные цифровые ориентиры российской системы управления как количественную характеристику. А они таковы: 2146 тыс. работников органов власти в РФ распределены по 3 уровням управления - федеральному, региональному и местному.

Отечественный исследователь Г.Л. Купряшин, исследуя всю сложность системы госуправления и анализируя имеющиеся в РФ модели (модель рациональной бюрократии, новое государственное управление, сетевая модель), интерпретирует процесс повышения результативности государственной бюрократии в рамках более академичной категории - «модернизации государственного управления». Под ней профессор МГУ понимает «формирование нового институционального дизайна, основанного на политическом целеполагании, учитывающем интересы инициирующих данный процесс властных групп и реализуемых через систему норм» [Купряшин 2011: 3].

Важно также иметь в виду, что реформирование системы госуправления в РФ, в т.ч. в ходе осуществления административной реформы 2004-2008 гг, давшей старт становлению модели «нового государственного управления», происходило с учетом международного научно-теоретического и практического опыта и в аспекте ключевого параметра эффективности. И в этой связи имеет смысл обратиться к классической работе Г.Дж. Фредриксона «Путь к новому государственному управлению», в которой автор дает понимание государственного управления как эффективного, экономного и скоординированного управления имеющимися в его распоряжении службами.

Г.Дж. Фредриксон в своем исследовании отмечает, что «обоснование государственного управления почти всегда означает лучший (более эффективный и экономный) менеджмент. Миссия же нового государственного управления добавляет к этому социальную справедливость» [Фредриксон 2003: 424]. Следовательно, считает автор, если традиционная, классическая теория государственного управления отвечает на два вопроса: как произвести больше услуг

\footnotetext{
1 Зачем России столько чиновников? 150 лет назад в стране приходилось 2 бюрократа на 1000 душ населения, сегодня - 15. - Аргументы и факты. 2017. № 27. Июль. С. 6-7.
} 
и обеспечить их высокое качество при эффективном распоряжении ресурсами, как сохранить прежний уровень услуг, тратя на это меньше денежных средств, то теория нового госуправления отвечает на более принципиальный вопрос: способствует ли государственная служба социальной справедливости?

Имеет смысл также сделать акцент и на том, что проблематика эффективности в сфере управления всегда занимала особое место в научных исследованиях. К примеру, экономист, социолог и политолог В. Парето уделял этому максимум внимания, концентрируя свои изыскания вокруг таких понятий и категорий, как «справедливо, похвально, желательно, нравственно необходимо» [Парето 2011: 34]. Такой подход в определении эффективности называют Паретоэффективностью. Таким образом, Парето-эффективность состоит в том, что общее (публичное) благо максимально при такой ситуации в экономике национальных государств, когда никто не может улучшить свое положение, не ухудшая положение другого. По направленности (условиям) это: 1) эффективность производства; 2) эффективность в структуре воспроизводства благ; 3) эффективность в распределении благ.

Последователи В. Парето, в частности даже либеральные исследователи, к примеру, М. Олсон, отмечали важность Парето-эффективности в сфере государственного управления. В ином случае в силу неэффективного госуправления возникают сильные побочные эффекты, «антиблага», приводящие к провалам рынка. М. Олсон в работе «Власть и процветание» называет их «экстерналиями». Ученый полагает, что потребление этих побочных эффектов «в условиях laissezfaire (франц. - позвольте сделать, либеральный принцип в экономике) является источником социальной неэффективности» [Олсон 2012: 77].

Важно полагать, что дефиниция эффективности является универсальной управленческой категорией, характерной как для сферы бизнеса, так и для системы государственного управления. Именно поэтому при проведении административной реформы в РФ в середине нулевых годов, когда в стране внедрялась модель нового государственного управления, в содержательном компоненте данной реформы были задействованы управленческие технологии и понятия из сферы бизнеса (услуги, клиенты, качество и др.). В данном разрезе значимым аспектом является теория динамической эффективности.

Над теорией динамической эффективности работали Л. фон Мизес [Мизес 2013; 2018], Ф. фон Хайек [Хайек 2016] (австрийская школа). Весомый вклад в теорию динамической эффективности внес И. Кирцнер, который определил само понятие динамической эффективности как ценности и способности, стимулирующей бизнес (предпринимательство) порождать новое знание, о котором до этого никто не знал и которое полезно для всего общества. И. Кирцнер полагал, что аспект знания, который действительно критически важен для предпринимательства, это не столько содержательное знание рынка, сколько бдительность, знание о том, где искать [Кирцнер 2010: 71].

Еще один последователь австрийской школы М. Ротбард достаточно критично оценивал идеал «статистической эффективности», называл ее мифом и в рамках теории динамической эффективности считал ключевой задачей управления (менеджмента) институционализацию этического контекста. Данный исследователь отмечал, что «этические цели должны формулироваться осмысленно» [Ротбард 2016: 301], предлагал установить некие границы конечных этических суждений, при этом не становясь моралистом.

В целостном же виде теория динамической эффективности обобщена и дополнена в работе Х. Уэрты де Сото, который проследил взаимосвязь между творческим, координирующим потенциалом предпринимательства («согла- 
сие на риски и опасности» [Уэрта 2011: 3]) и системой этических принципов общества. Ракурс его исследования - динамический аспект эффективности.

Эффективность системы государственного управления логично рассматривать и через изучение качества институтов. В этой связи для понимания сущности эффективности в неоинституциональном разрезе Д. Норт предложил в научном дискурсе идею «адаптивной эффективности». Д. Норт отмечает, что «институты - это “правила игры” в обществе или, выражаясь более формально, созданные человеком ограничительные рамки» [Норт 1997: 17], которые организуют взаимоотношения между людьми. Следовательно, согласно автору, такие институты (правила игры) задают структуру побудительных мотивов.

Еще один ракурс в проблематике анализа эффективности предложил в своем исследовании X. Лейбенстайн, введя в научный оборот понятие аллокативной эффективности ( $x$-эффективность). Речь идет о системе управления, при которой особое внимание уделяется удачному размещению ресурсов (продуктов) в интересах общего (публичного) блага. Основным элементом $x$-эффективности в исследовании Х. Лейбенстайна является мотивация, поскольку «ни отдельные люди, ни фирмы не работают так хорошо и не ведут поиск так эффективно, как могли бы» [Лейбенстайн 1999: 496]. Данный ученый в своем исследовании выделяет следующие виды мотивации: 1) внутриорганизационную мотивационную эффективность; 2) внешнюю мотивационную эффективность и 3) эффективность нерыночных ресурсов.

Резюмируя, следует отметить, что категория эффективности, находясь в междисциплинарном измерении, со всей очевидностью применима к деятельности органов власти и управления. На основе имеющихся исследований в отечественном и зарубежном научном дискурсах разработан основательный методологический фундамент для практикоориентированных методик замера эффективности деятельности органов власти и управления.

\section{Список литературы}

Кирцнер И. 2010. Конкуренция и предпринимательство (пер. с англ. А.В. Куряева, Д.А. Бабушкина; под ред. А.В. Куряева). М.; Челябинск: Социум. 282 с.

Конструирование современной политики в России: институциональные проблемы (отв. ред. С.В. Патрушев, Л.Е. Филиппова). 2018. М.: Политическая энциклопедия. 262 с.

Купряшин Г.Л. 2011. Институциональный дизайн и концептуальные ориентиры модернизации государственного управления. - Государственное управление. Электронный вестник. Вып. 26. С. 1-14.

Лейбенстайн X. 1999. Аллокативная эффективность в сравнении с «Х-эффективностью». - Вехи экономической мысли. Т. 2. Теория фирмы. СПб: Экономическая школа. С. 477-506.

Мизес фон Л. 2013. Теория и история: интерпретация социально-экономической эволюции (пер. с англ. А.В. Куряева). М.; Челябинск: Социум. 368 с.

Мизес фон Л. 2018. Человеческая деятельность: трактат по экономической теории (пер. А.В. Куряева с 3-го испр. англ. изд.). М.; Челябинск: Социум. 878 с.

Норт Д. 1997. Институты, институциональные изменения и функционирование экономики (пер. с англ. А.Н. Нестеренко; предисл. и науч. ред. Б.З. Мильнера). М.: Фонд экономической книги «Начала». 180 с.

Олсон М. 2012. Власть и процветание. Перерастая коммунистические и капиталистические диктатуры. М.: Новое издательство. 212 с.

Парето В. 2011. Трансформация демократии (пер. с итал. М. Юсима). М.: ИД «Территория будущего». 208 с. 
Ротбард М. 2016. Власть и рынок: государство и экономика (пер с англ. Б. Пинскера, под ред. Г. Сапова). М.; Челябинск: Социум. 418 с.

Уэрта де Сото Х. 2011. Социально-экономическая теория динамической эффективности (пер с англ. В. Кошкина, под ред. А. Куряева). Челябинск: Социум. $409 \mathrm{c}$.

Фредриксон Г. Дж. 2003. Путь к новому государственному управлению. Классики теории государственного управления: американская школа (под ред. Дж. Шафритца, А. Хайда). М.: Изд-во МГУ. С. 423-441.

Хайек фон Ф. 2016. Право, законодательство и свобода: современное понимание либеральных принципов справедливости и политики (пер. с англ. Б. Пинскера, А. Кустарева, под ред. А. Куряева). М.; Челябинск: ИРИСЭН; Социум. 644 с.

Шмитт К. 2016. Понятие политического (пер. с нем., под ред. А.Ф. Филиппова). СПб: Наука. 568 с.

SOKOLOV Vadim Vyacheslavovich, Cand.Sci. (Hist.), Associate Professor; Associate Professor of the Chair of Political Science and State Policy, Central Russian Institute of Management - Branch of the Russian Presidential Academy of National Economy and Public Administration (RANEPA) (5a Pobedy Blv, Orel, Russia, 302028; politgmu@mail.ru)

\title{
ON THE ISSUE OF THE CATEGORY OF EFFICIENCY IN ACTIVITY OF BODIES OF AUTHORITY AND MANAGEMENT IN RUSSIAN AND FOREIGN SCIENTIFIC DISCOURSES
}

\begin{abstract}
The article discusses the categories that characterize management efficiency issues. The author analyzes such concepts as political, management, authorities, efficiency in Anglo-Saxon and Russian political science. The concept of efficiency is considered both as a universal managerial category, and as a unit of the public administration system. On the base of the analysis performed, the author reveals a causal relationship between political conditions and an increase in the effectiveness of activities of the authorities and administration in the Russian Federation.
\end{abstract}

Keywords: political, management, government, authorities, efficiency 